\title{
THE ROLE OF A JOURNALIST IN AGRICULTURAL EXTENSION
}

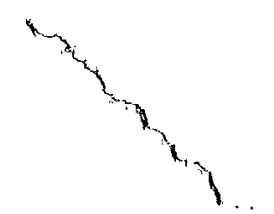

\author{
D. L. FYFE \\ Christchurch
}

LAST YEAR the Grassland Memorial Trust was kind enough to make me one of their annual awards, and as one who works mainly in the field of agricultural journalism I feel that it may be interesting, though I doubt of very much real value, if I set down a few rambling thoughts about communication in agriculture.

In a way communication is a very important matter in agriculture - I feel one of the most important. It is involved in helping the farmer to grow his pastures and crops, handle his livestock, and manage his farm to best advantage. It is not a precise art because no two farmers are the same and react differently to advice or guidance, but. because of its basic importance it is perhaps not given the 'attention that it deserves.

It has been my feeling since I first attended a conference of the New Zealand Grassland Association at Dunedin in 1958 that the Association has a high awareness of the importance and value of communication among scientist, advisory officer and farmer.

The Association could well be an organization of grassland and other scientists and of professional adviser's, but it is. much more than that in that it includes among its members a goodly sprinkling of farmers. Its annual conference's, held in a different part of the country each year, with farmers in those districts , being freely invited to attend, are a happy blending of all these groups.

These conferences tend to place emphasis on the problems in the particular area in which they are held and consequently have an educational 1 function for the farmers who attend and also for other farmers through the attention that is given to them through the news media and farming publications.

The field days that are an integral 'part of the conferences mean that 'all the groups go out into the countryside' and see it at first hand. It is an opportunity then for scientists and advisers from other parts of the country not oaly to hear but also to see at first hand the problems of farming in another area. The opportunities 
that these gatherings provide for exchange between farmers and the other groups ensure that grassland scientists, at least, do not live in ivory towers and are aware of what are the pressing problems on the land. I remember the good-natured and meaningfir 1 exchange's that took place between the late Dr Peter Sears and farmers during a field day trip in the Bay of Plenty in 1961.

The conferences, too, provide an opportunity for grassland scientists to report on their investigations for the benefit of their fellows and of farmers, and, because farmers are among their listeners, in a more practicall and meaningful way than might otherwise be the case.

It is, perhaps, a pity that moire farmers in the districts where these meetings are being held do not take advantage of these opportunities. The Association and those in local areas who organize these meetings, might well give thought as to how these numbers can be increased, but I do not think that this is something that can be carried too far.

While I say that the field of communication in agriculture has not been accorded the importance that it deserves, I would also say quite emphatically that one cannot hope to saturate the country with the science and practice 04 one particular field of interest.

Farmers are not all prepared to put down tools and go to a conference or field day though it might well be more beneficial to them than doing some menial job at home that could well wait until tomorrow to complete. It is often the best informed and most successful farmers' who regularly attend conferences and field days. It is likely always to remain that way. But through radio, television and other news media a wider audience can be reached and interest prodded, and in the long run agricultural practice and skill and progress can be promoted and advanced.

I said before that all this is not a precise art because farmers are all different people. It is for this reason that agricultural communication and extension must take many forms - through conferences, field days, radio, television, farming journals, newspapers, Government advisory officers, private consultants, farm improvement clubs, advisers of commercial firms, and so on. Each has a place. Some overlapping is inevitable, but I believe must be accepted because of the diversity of farmers and farming conditions. It might be nice to rationalize all of this, but I believe that it is not possible.

The scientist has a responsibility to report simply to the advisory officer and the farmer when he has something to report. 
There have been cases of people hiding their lights under a bushel. This is unfair when frequently their work is funded by the taxpayer's money. On the other hand there is a happy medium to all of this. The scientist must have something to contribute to warrant an exercise in communication. Some training in this area for scientists might not go amiss.

There is a place for people versed in communications working with organizations in the scientific field. They have the time and the skill to present in a readable but still useful style the sort of information that should be passed on to the farmer, when the news media may not have the time and staff to do these things themselves. These specialists in scientific and like organizations can usefully supplement the work of agricultural and other journalists in radio, farming publications and newspapers. I am thinking here of the concise and useful articles about work in the Department of Scientific and Industrial Research periodically distributed to newspapers serving farming areas by a person like M. J. Roche.

Considering its size, New Zealand is reasonably well served by specialist farming journals, by the radio and television, and by some newspapers who devote attention to farming matters.

Although a very important part of the population, farmers, however, constitute only a fairly small part of the population and consequently cannot expect the media to devote an undue proportion of their time and space to the industry. There is an obstacle, too, in that farming information is something that is often not seen as being very newsworthy. In the eyes of some, farming only makes news when a member of Federated Farmers makes an outrageous allegation or there is a slump or boom.

To my mind the Grassland Association has established the right sort of balance. It should be jealous of the blend that it has achieved among scientists, advisers and farmers. It should be cultivated. It is an example to other organizations working in the agricultural field.

I was heartened to find at last year's conference of the Association at Oamaru that it is coascioas of this special position. It had before it a proposal that every second year, for the benefit of its more scientifically inclined members, a half-day session of a technical nature should be held in conjunction with the convention of the. New Zealaod Institute of Agricultural Science, which now provides an opportunity for a number of organizations associated with agriculture to hold sessions at the same time. There was nothing very sinister about this proposition, but it was re- 
jected in favour of a half-day of papers of a technical nature being incorporated in the Association's next annual conference at Hastings.

Opposing the proposal for a separate technical session at the Institute convention, Dr R. W. Brougham, Director of the Grasslands Division of the Department of Scientific and Industrial Research, said that farmer participation was the key to the success of the Association. He said that he did not think that there was a comprehension gap between farmers and research workers. Some of the most intelligent observations he had heard had been made by farmers. Why should farmers not participate in technical discussions at the conference?

W. G. Thurston, technical editor of the Association, said that the holding of a separate technical session outside the conference could drive a wedge between farmers and others in the Association.

There were quite reasonable and valid arguments advanced in favour of a session being held at the Institute of Agricultural Science convention, but it was defeated in favour of the unimpaired unity among scientific and other interests in the Association.

I would award the Grassland Association the first prize among all organizations in the agricultural field for keeping contact with its constituents. 